\title{
Marketing the Prosthesis: Supercrip and Superhuman Narratives in Contemporary Cultural Representations
}

\author{
Chia Wei Fahn (D) \\ Department of Foreign Languages and Literature, National Sun Yet-sen University, Kaohsiung 80424, Taiwan; \\ celinefahn@gmail.com
}

Received: 24 February 2020; Accepted: 7 July 2020; Published: 10 July 2020

check for updates

\begin{abstract}
This paper examines prosthetic technology in the context of posthumanism and disability studies. The following research discusses the posthuman subject in contemporary times, focusing on prosthetic applications to deliberate how the disabled body is empowered through prosthetic enhancement and cultural representations. The disability market both intersects and transcends race, religion, and gender; the promise of technology bettering the human condition is its ultimate product. Bionic technology, in particular, is a burgeoning field; our engineering skills already show promise of a future where physical impediment will be almost obsolete. I aim to cross-examine empowering marketing images and phrases embedded in cinema and media that emphasize how disability becomes super-ability with prosthetic enhancement. Though the benefits of biotechnology are most empowering to the disabled population, further scrutiny raises a number of paradoxical questions exposed by the market's advance. With all these tools at our disposal, why is it that the disabled have yet to reap the rewards? How are disabled bodies, biotechnology, and posthuman possibilities commodified and commercialized? Most importantly, what impact will this have on our society? This paper exemplifies empowering and inclusive messages emphasized in disabled representation, as well as raising bioethical concerns that fuel the ongoing debate of the technological haves and have-nots. Furthermore, this paper challenges the ideals of normative bodies while depicting the disabled as an open, embodied site where technology, corporeality, and sociology interact. To conclude, I believe that an interdisciplinary approach that balances the debate between scientific advance, capital gain, and social equality is essential to embracing diverse forms of embodiment.
\end{abstract}

Keywords: bionics; prosthesis; biotechnology; disability; marketing; cultural studies; Disney; supercrip

\section{Introduction}

Studies in both natural sciences and the humanities have been devoted for much of the last two decades to exploring how biotechnology revolutionizes human interaction with our material surroundings. From bifocal glasses to high performance prosthetic limbs, hearing aids, and pacemakers, the conjuncture between the human body and biotechnology is expanded by various forms of prosthetic extensions. Human bodies are now seen by some commentators as "machines to be fine-tuned and perfected through add-ons," as the body is continuously augmented and its capabilities enhanced [1] (p. 248). A humanist view of the body as a coherent, self-contained, and autonomous self is no longer applicable; biotechnology has led to a most significant shift in body politics that views the body as a network or assemblage that is constantly evolving with technology. The relationship between human bodies and biotechnology is symbiotic, working "in between the points of contact linking bodies and technologies to configure them differently" [2] (pp. 3-4). This reconfiguration of the body and technology is most prominently seen in bionic engineering, with the infinite possibilities of technological progress materialized through prosthetic limbs, optics, and organs [3]. Traditionally perceived as a visual reminder of our vulnerability that signifies "physical and metaphysical lack," 
prosthetics have become a corporeal extension that empowers the disabled body, allowing the human body to transcend boundaries and limitations [4].

The interrogation of the permeability of corporeal boundaries sparked an ongoing body of work that examines the "continuous deconstruction and reconstruction" of embodiment [5]. Prosthetic technology destabilizes the human boundaries, with Donna Haraway's famous question: "Why should our bodies end at the skin?" urging discourses that extend posthuman concepts of the body to rise in response [6]. Applied prosthetics demonstrate "the ultimate expression of human control-helping us shape and define the way we would like to be," contributing to new forms of embodiment in the posthuman subject [7]. This posthuman subject embraces the body as unstable and "refers to the destabilization and unsettling of boundaries between human and machine, nature and culture, and mind and body that digital and biotechnologies are seen to engendering" [8]. In other words, the posthuman traces a different discursive framework that affirms forms of alternative embodiment and opens the body as an extended, distributed, interconnected, and relational entity. Posthumanist thought views human subjectivity as an assemblage that evolves in conjunction with machines, animals, and the environment.

Our bodies have become fluid and ambiguous, disrupting binaries such as human versus non-human, and able-bodied versus disability. With prosthetic technology constantly pushing the boundaries of physical limitation, the disabled body is now regarded as an intricately diverse site of interdisciplinary discourse. Scholars in the field focus their efforts on subverting our body concept, social constructions, and disputes by exploring the relationship between disabled bodies and applied prosthetics [9]. Their efforts place disabled bodies at the nucleus of progress in assistive technology that no longer casts the body in a "dualistic frame, but bears a privileged bond with multiple others and merges with one's technologically mediated planetary environment" [10] (p. 92). Social and material debate in disability studies has emerged with the "new connections among rediscovered agencies and thereby dethrones the ideal of a human cognitive, physical, emotional normal" [11] (p. 310). Therefore, a posthuman approach to disability recognizes a new ethics of the body that is embodied in "the conceptual edges between 'the human' and 'the posthuman,' the organic and the mechanic, the evolutionary and the postevolutionary, and flesh and its accompanying technologies" [2] (p. 3). I believe the disabled body represents a versatile embodiment of these conceptual edges and is most reflective of social change. By a juxtaposition of textual analysis and case examples in both popular culture and practical use, this paper examines the rising trend of empowering disabled bodies that focuses on the bionic industry.

Groundbreaking research in bionic limbs and neurotransmission poses a direct challenge to the limitations of humanity and human performance. Bionic technology is a burgeoning market; our engineering technologies already show promise of a future where physical impediment will be almost obsolete. The following research reflects on the posthuman subject in contemporary times, focusing on prosthetic applications to deliberate how the disabled body is empowered through prosthetic enhancement and cultural representations. I aim to cross-examine marketing images and phrases embedded in the fields of sports, cinema, and media that portray the prosthesis as empowering to emphasize how disability becomes super-ability with prosthetic enhancement. Bionic prosthetics are heavily promoted in contemporary film and media, a trend I will thoroughly review by exemplifying innovative work in the field as well as addressing future possibilities that include the freedom to alter our bodies in all forms and functions.

Though the benefits of biotechnology are most empowering to the disabled population, further scrutiny raises a number of paradoxical questions exposed by the market's advance. With all these tools at our disposal, why is it that the disabled have yet to reap the rewards? How are disabled bodies, biotechnology, and posthuman possibilities commodified and commercialized? Most importantly, what impact will this have on our society? Living in the times of the posthuman, I advocate various ways of becoming that embrace a sustainable ethics of transformations that emphasize the future of embodiment in real bodies. In other words, the future of posthuman embodiment should not only 
be in pursuit of "glamorous cyborgs," but also in creating a sustainable future that provides equal access to advanced technology and all its promised opportunities. This should especially apply to the "anonymous masses of the underpaid, digital proletariat who fuel the technology-driven global economy without ever accessing it themselves" [10] (p. 90). However, under the current market mechanism, I am more concerned that the uneven distribution of technological resources and restrictive access to biotechnology create a new social caste, an issue I aim to address in the following analysis of enhancement technologies.

\section{Disabled Bodies and the Prosthesis-Transcending Physical Boundaries and Embodying Posthuman Possibilities}

Posthuman embodiment focuses on the body as a constant state of becoming that includes shifting social paradigms and political subjectivities $[1,10,12]$. The disabled body embodies new interactions with our material environment as well as with each other; disability studies is therefore "perfectly at ease with the posthuman" because "disability has always contravened the traditional classical humanist conception of what it means to be human" and responds directly to the complex diversities in our contemporary society [13] (p. 342). An intersecting dialogue, however, has only emerged in the last decade, with Rosi Braidotti's The Posthuman (2013). Braidotti asserted that disability studies "combine the critique of normative bodily models with the advocacy of new, creative models of embodiment," affirming the disabled body as an open, embodied site where technology, corporeality, and sociology interact [10] (p. 146). With bionic technology, the human body is transformed into "a module onto which various technological additions can be attached ... technology is not separate but part of the body" [14] (p. 241). Braidotti's viewpoint resonates with Davis' concept of dismodernism; both challenge the body's boundaries to explore the openness of disabled bodies and forge interdisciplinary connections. In this regard, disability studies becomes an exemplary network of various intersecting discourses.

The work of Margrit Shildrick furthers the idea of a fluid, posthuman body that is embodied by the disabled; she believes that the disabled body, the prosthetic body, and normative bodies are all a "profound interconnectivity of all embodied social relations" that is "simply one mode among multiple ways of becoming" [15] (p. 8). Shildrick's perspective expounds upon Katherine N. Hayles' posthuman analysis; both addressed the relationship between human limitations and the utilization of supplementary devices in facilitating day-to-day living conveniences. Hayles advocated for a "posthuman view ... of the body as the original prosthesis we all learn to manipulate, so that extending or replacing the body with other prostheses becomes a continuation of a process that began before we were born" [5] (p. 3). Consequently, technological growth and innovative design are now seen as having a unique influence regarding disability and posthumanism; disabled bodies are a "dynamic hybrid" that is focused "not on borders but on conduits and pathways, not on containment but on leakages, not on stasis but on movements of bodies, information and particles" that transcend corporeal boundaries and join the biological to the technological in posthuman embodiment [12] (p. 10).

According to Braidotti, the human condition is expanded by "the four horsemen of the posthuman apocalypse: nanotechnology, biotechnology, information technology and cognitive science" [10] (p. 59), causing "the boundaries between 'Man' and his others [to] go tumbling down, in a cascade effect that opens up unexpected perspective" [10] (pp. 66-67). The disabled subject affirms connections between the body and technologies that is the quintessential posthuman condition [16]. Nayar built upon this concept of transcending physical boundaries to study posthuman embodiment in disabled bodies, stating that "the differently abled ... exist on the other side of the border. It is this issue of boundary-marking and personhood that brings disability studies and bioethics into the ambit of critical posthumanism" [12] (p. 101). Disabled bodies interrogate existing normative standards of the human subject, contributing significantly to posthumanist thought by calling attention to a deconstruction of the deviance and normalcy that regulate the body. Disability disarms and disrupts the normative assumptions about what it means to be human; it extends and expands into perspectives that look affirmatively towards alternative modes of embodiment. 
A posthuman subjectivity is based on creativity and the opening up of possibilities. With prosthetic technology we will have the tools to redesign and reinvent the body; prosthetics are an invitation to reconsider notions of normality, function, and ability. The push to realize posthuman possibilities and alternative embodiment has led to progressive development in bionic augmentation and neurotransmission technology. Today, we have a selection of prosthetics that range from plastic surgery injections to full-bodied exoskeleton suits that enable the paralyzed to stand, walk, and even run again-the development of prosthetic tools that not only seek to mimic human function, but also enhance the body's capacity. Disabled bodies present a means to enhance humanity and transcend physical limitations, and with that recognition came a shift in the portrayal of disability as well as an emerging disability-related market. The following discussion explores how disability is increasingly portrayed in empowering cultural representations as posthuman, examining the "embodiment and embeddedness" of the human being that integrate the biological with the technological [17] (pp. $\mathrm{xv}-\mathrm{xvi}$ ). Following a transitory dialogue from disability to the posthuman, I aim to bring an interdisciplinary discourse on posthuman embodiment into consideration with the biotechnologies that evoke fundamental changes in the body and our society, with a special focus on prosthetic limbs and the bionic industry.

\section{Disability (Broadly Defined) and Commercial Trends: Subverting Norms and Creating a Limitless Market}

In 2010, Snyder and Mitchell identified contemporary times as a new era of social inclusion that "open[s] rhetorical claims of a new era of inclusion for people with disabilities" [18] (p. 116). Their work calls attention to the global reality of disabled populations, with a special focus on the role of disability and disabled bodies in the consumer market. Disability was seen in the past as a visual reminder of human imperfection; however, with recent developments in biotechnology, the disabled body is transformed into a canvas for augmentation as technology turns the disabled body into a marketable commodity by "selling one's capacities (and, now, incapacities) in a market economy" [18] (p. 121). Over the last two decades, disability-related markets have been identified as the largest and fastest-growing subgroup in the United States, with Forbes magazine estimating the scope of this "overlooked and growing market" to be limitless [19]. Marketing groups such as Fifth Quadrant Analytics, Sutton Marketing, and the LinkedIn platform now offer consulting services to companies that wish to capitalize upon a targeted disabled demographic that is seen as the world's "next big consumer segment" [19].

Technological designs not only target people with disabilities as a core consumer base, but appeal to "healthy" people who share the inevitability of disability [20] (p. 8). Disability is an inherent part of the human condition; the understanding that "everyone will be disabled if they live long enough" has been "an incredibly generative disability studies insight," from contact lens to pacemakers, products that address the broad definition of disability have led related businesses to form the world's fastest growing market [21] (p. 200). The human condition is "in fact disabled, only completed by technology and by interventions," establishing how the boundaries between ability and disability are open and subject to change as a result of productive needs and the utilization of extended tools [15] (p. 241). Davis sees a new ethics of the body in this commercial trend and focuses on the care of the body as "a requirement for existence in a consumer society"; our bathrooms alone hold an arsenal of tools catering to individual needs [22]. The knowledge required to design these products originates from an understanding of our physical lack and impairments, rendering forms of biological data into the ultimate commodity of the twenty-first century.

Progress in medical and reproductive fields is built upon the study of disabled and abject bodies and has bettered the lives of those who live with disability and disease. Disabled people provide physical data for the "micro-management of information and bodies" that lead to biotechnological breakthroughs [18] (p. 117). Disability is commercialized "in the popular sphere of product advertisements," disabled bodies are ubiquitously featured in commercials for "pharmaceuticals, 
prosthetically engineered bodies and minds, mutating organisms that may be better adapted for a future world yet to come" [18] (p. 117). The niche markets of disability create opportunities that "catalyze radical new approaches-approaches that might subsequently have more widespread applications" resulting in innovative designs that are marketable to both disabled and non-disabled groups [23]. Disabled bodies become both a saleable commodity and a target demographic as technological development expands the new market for body and body matters. This phenomenon benefits the disabled both physically and financially; biotechnological businesses are creating job positions that tap into disabled people's unique insights and embodied experience. Tusler focused on instrumentalizing disabled people for corporations to serve the technological industry in How to Create Disability Access to Technology, arguing that the "challenge of being successful has led many people with disabilities to be skilled problem solvers and consumers-making them valuable assets" [24]. In 2014, LinkedIn published an article titled "Ten Ways to Target the Disability Market \& Keep a Competitive Edge," urging companies to develop an inclusive and comprehensive diversity strategy that incorporates product design, marketing, and, most of all, insures "a marketing strategy and mechanism that builds a company's brand as an inclusive workplace committed to equality and to hiring, retaining and promoting people with disabilities" [25]. This foray into disabled employment and the communicative understanding of disabled needs that focuses on providing product choices has opened employment opportunities catering to the disabled population and subverted able-bodied norms previously dictating the job market.

Inclusive efforts in product and strategy design have furthered empowerment through the increased visibility and representation of disabled persons, while allowing the disabled to contribute their unique perspective to professional knowledge in product design. The disabled perspective and embodied experience are highly instrumental in the development of assistive technology, leading to exponential industrial growth in the area of bionic prostheses. Subversive narratives of physical empowerment and accessibility are most prevalent in marketing prosthetic and bionic limbs. The advent of social media and transparent communications has also resulted in considerable changes in brand image presentation, with tales of inclusive products heavily promoting demonstrations of empowering people with disabilities [26]. Representations of prosthetic technology have progressed in a drastic shift from supplementing the disabled body and creating a normalized image to representing the physical embodiment of enhanced power through prosthetic augmentation.

The disability-related market both intersects and transcends race, religion, and gender; the promise of technology bettering the human condition is its ultimate product. An analysis of media advertisements featuring disability finds that messages of empowerment and inclusion, as opposed to stigmatizing portrayals, are a common theme [27]. Market recognition, universal product design, and inclusive representation all contribute to furthering social and individual empowerment in the disabled community. With increasing advances in prosthetic limbs and bionic technology, portrayals of people who use such devices accentuate enhanced physical competence that surpasses even the able-bodied, a narrative that rewrites social attitudes toward the prostheses and also disrupts the disabled stereotype. At the same time, an increase in disabled representation serves as a positive advertisement for brands and merchandise alike, promoting corporal images in an era that markets social inclusion. In turn, these portrayals also subvert the traditional stigma of normalized bodies and display how the disabling aspects of a differently-abled body can also be empowering. This transition from disabled to super-abled changes, albeit slowly, how we regard the disabled body and acclimatizes the public to alternative forms of posthuman embodiment in contemporary practices. In the following sections I will elaborate on the shift in social narrative, with a special focus on limb disability and the cultural representations of prosthetic enhancement.

\section{From Disabled to Super-Abled: Commercializing the Supercrip Narrative in Film and Media}

Supercrip is an encompassing term traditionally representing inspirational, disabled people. In the past, the supercrip was extensively criticized for its depiction of disabled people who overcome 
spiritual and physical challenges to perform everyday tasks, revealing the low expectations from normalized society [28-34]. An affirming support of supercrip narratives has risen in recent years, however, to support the portrayal of disabled people who are "brave for defying expectations"; disabled people are urged to recognize that "our actions are purposeful, our art exciting, or our words meaningful, we do inspire" [35] (p. 198). Building upon this support is Goodley and Runswick-Cole's argument that the disabled body has always demanded to be recognized not as an embodiment of lack, but of possibility [20]. This demonstrates a shift in perspective that forms the nexus of this paper; subversive representations of disability promote empowerment not in the ability to overcome, but in the different abilities presented through an alternative embodiment that transcends the confines of physical normalcy.

The 2015 film Mad Max: Fury Road provides an inspiring example of physical empowerment with the disabled character "Furiosa." In a movie filled with male characters and battle scenes, Furiosa stands out as an emblem of indisputable power. In a much-discussed scene, Furiosa punches the titular Max in the face with her amputated stub, exuding an on-screen strength that subverts both norm and form. Furiosa's disability is not depicted as a challenge to be overcome, nor is her physical lack portrayed as a vulnerability. Furiosa is defined by her abilities, not her infirmities; the character radiates power that transcends the physical category [36]. Furiosa's scene is powerful because of the matter-of-fact treatment of her body. She embraces her form and utilizes it fully; Furiosa's body just is. This supercrip portrayal subverts the norm of frail and fragile disabled imagery and draws the viewer's attention to ability, not disability. The result is undoubtedly empowering, yet also raises concerns over a new form of ableist expectation that subjugates the body, an issue I will discuss in the following sections.

In recognition of empowering portrayals of the disabled body, Sami Schalk called for a reevaluation of the supercrip stereotype to build a "future scholarship to interrogate supercrip representations in a variety of cultural arenas," arguing that "to dismiss outright all representations of supercrips as 'bad' is to disregard potentially entire genres of popular culture productions, ones which tend to have very large audiences" [29] (p. 84). Schalk focused on the mechanisms of supercrip narratives, proposing that "supercrip narratives produce ... representations of purportedly extraordinary disabled people of three distinct, yet related types" [29] (p. 79). A "regular" supercrip narrative exemplifies disabled persons who are able to execute normalized tasks; the "glorified" supercrip narrative portrays accomplishments that challenge the non-disabled; and the "superpowered" supercrip narrative emphasizes transhuman power [29]. Advances in prosthetics and assistive technology further transformed the supercrip narrative from overcoming physical trials to sensationalizing the technological superhuman [37]. The rapid change in the lived-in reality of disability is reflected in supercrip representations embodying messages of power and interdependency, as the supercrip "amazes and inspires the viewer by performing feats that the nondisabled viewer cannot imagine doing" [38] (p. 71). These representations embody possible futures in posthuman development and demonstrate paradigm shifts in the representations of disability.

Science and technology offer a transcendent way of life that far surpasses rehabilitation or even the normalized body [39-42]. Technological cures "enable ... an enhanced functionality" that allows the body to become "stronger, faster, or more responsive" [43]. Prosthetic augmentations create a techno-posthuman world "with science as the rescuer of the human from its mortal self ... the human becomes an assemblage of parts, conceived of in terms of a machine that can be ... repaired, and redesigned" [1] (p. 260). With augmented technology rapidly becoming accessible to the disabled population, the rebranding of prosthetics as a means of physical empowerment is most prominently seen in film and popular media, exploring "deviant and disabled bodies ... whose embodiments are situated along the entire spectrum of ability" [42] (p. 2). A vast body of works that subvert the abject to heroic either popularizes heroes whose marked disability becomes their superpower, or showcases individuals who gain superhuman capabilities through prosthetic augmentation. From the paraplegic Professor X and the blind Daredevil, to the bionically-sustained Cyborg, disability is portrayed as 
the capability to "conjure a world in which freaks, crips, gimps ... cultivate a unique power and perspective outside ... conformity" [44]. Prosthetically-enhanced supercrips, in particular, became inspiring images designed to appeal to the general public, images that also represent alternative, posthuman embodiments. These portrayals fuel the disabled consumer market, advertising physical empowerment and unlimited possibilities that can be gained through the use of advanced prosthetics.

Empowering prosthetics are prominently featured in Marvel Studio's Iron Man, with titular figure Tony Stark transforming from a disabled and disillusioned playboy to world-saving superhero in an exoskeleton suit. At the beginning of the film, Stark is fatally wounded by an explosion that sends shrapnel flying into his chest cavity, entering his bloodstream to gradually make its way toward his heart. To prevent certain death, Stark inserts a miniature reactor into his chest that generates a magnetic protective field with the added benefits of powering a full-body bionic suit. Though the Iron Man comics debuted in 1968, the flawed and disabled hero is now an iconic figure in the contemporary marketing of bionic enhancement. The Iron Man franchise does not label Tony Stark as a triumphant hero rising above physical impairment; Stark's disability neither defines nor confines him. Instead, the piece of shrapnel in Stark's chest is motivation to continuously navigate new technology that improves his state of living. Physical empowerment through prosthetic technology is a consistent theme throughout the series, as Stark continues to improve upon his initial creation. With each installment of the Iron Man trilogy, viewers see an upgrade in Stark's armor, with Stark becoming increasingly powerful through the integration of mechanical engineering and biotechnological science. Stark is a prime example of the superpowered, supercrip narrative utilized in contemporary film that aims to change society's perception of physical disability through empowering representations of high-functioning prosthetics.

Contemporary technology has yet to match Stark's AI-navigated, G-force-defying Iron Man suit, though the concept of a bionic bodysuit has been manufactured and proven highly functional. A product test video released in 2014 by California-based company Ekso Bionics portrays paraplegic woman Amanda Boxtel walking for the first time in 22 years while encased in a 3D printed exoskeleton suit. A bionic exoskeleton suit of similar design was featured two years later in Captain America: Civil War, allowing Stark's friend to walk again after suffering severe spinal injuries. The exoskeleton suit allows the paralyzed to regain mobility, inspiring various designs and working prototypes from bionic engineering companies such as Rex Biotics, ReWalk Robotics, and SuitX. The ReWalk exoskeleton, for example, uses inertial sensors to detect subtle changes in the user's center of gravity to provide a natural gait and stair-climbing abilities [45]. Exoskeleton suits were prominently featured in a series of promotion videos for the Cybathlon 2016 competitions held in Kloten, Switzerland, as an integral part of the unique championship for people with disabilities to compete in completing everyday tasks with the aid of state-of-the-art assistive technologies [34] (pp. 14-15). In China, preliminary tests on a wheelchair and exo-suit hybrid were conducted and results published in 2019, with engineers working to elevate motion assistance and motor ability for wheelchair users. Users can move from sitting to standing positions by changing the mechanical configuration on motorized wheelchairs, and an exoskeleton function provides movement in knee and hip joints that enables the user to walk. Apart from an increase in mobility, this also puts forth a solution for complications related to long-term sitting, such as pressure sores, muscle atrophy, and bladder infections [46]. Although the user's body remains encased in an assistive prosthesis, both suit and wheelchair represent empowerment instead of confinement.

The bionic bodysuit demonstrates a future where physical disabilities are transcended through technology. This injection of science-fiction-inspired technology into the source material not only serves as a demonstration of technological capacity, but also blurs the line between literary imagination and scientific reality, as science inspired by fiction intrinsically weaves into the fabric of contemporary reality. Later installments in the film franchise introduced an antihero named the Winter Soldier, an amputee with an ultra-strong cybernetic arm that lends him extreme strength and dexterity in battle. Marvel's Winter Soldier brought the franchise back from futuristic possibilities in augmented physicality to a more conventional form of prosthesis, leaving fans enthralled by the return to an 
identifiable narrative as the Winter Soldier struggles with PTSD while performing extraordinary feats in hand-to-hand combat. The following year, Marvel's mother company Disney Inc. announced a new line of prosthetic limbs co-developed by the UK company Open Bionics that were based on the same designs as worn by the main characters in their Star Wars and Iron Man franchises. Open Bionics is part of the Disney Accelerator program, an incubating branch of the Disney Corporation that invests in new technology and media companies specializing in products that span virtual reality, artificial intelligence, and robotics. Disney makes equity investments in each of the 11 participating companies through undisclosed amounts of funding, with the companies receiving guidance from Disney marketing executives, investors, and established leaders in the industry. The start-up tech company specializes in creating prosthetic cybernetic arms that operate using sensors attached to the skin in order to detect muscle movements. These muscle movements control the hand and open and close the fingers, allowing users to enjoy mobility currently unavailable in traditional prosthetics. This new line of bionic limbs either features concept art inspired by fan favorite characters, or in the case of the Winter Soldier and Iron Man, boasts identical designs to the original.

Open Bionics' company website expounds upon its goal of building and developing the next generation of bionic limbs and turning disabilities into superpowers. Named the "Hero Arm," the superhero-inspired, Disney-branded bionic arms aim to promote the same sense of empowerment as their film counterparts, making users "feel like superheroes" [47]. With the Hero Arm, a user's "limb difference is your very own superpower" [47]. Limbitless Solutions, a 3D printing company, also designs bionic arms inspired by Iron Man's super-powered gauntlets. The company's promotional video of Robert Downey Jr. delivering a 3D-printed prosthetic arm to a disabled child in 2015 is an example of how science fiction is "used in contemporary social media to promote new technology" [48]. These collaborations between film franchises and the bionic industry mark a first in brand marketing as well as indicate a clear recognition of the expansive opportunities in the disability market. High-functioning prosthetics have now been branded with a "superhero" image that lends power to those who use them. The superpowered, supercrip narrative not only offers "counter discursive forays" into the public perception of disability, but also empowers the disabled through physical advantages that have been widely publicized in popular media [49]. The following section examines these augmentative advantages in media representation.

\section{From Supercrip to Superhuman-Disability as an "Unfair" Advantage}

In addition to film representations of prosthetic empowerment, popular media have also become a platform for the superpowered supercrip narrative and product demonstration. Websites such as YouTube, Facebook, and Instagram provide an open and indiscriminative medium for the disabled to share their stories and for innovators to display the latest breakthroughs in technology. Through YouTube videos, the prosthetically enhanced are able to construct and popularize narratives that emphasize their capabilities instead of disability. The disabled gain power through public viewership that subverts the oppressive, able-bodied gaze on the disabled body, and seize control of rhetoric and perception. Rosemarie Garland-Thomson elaborated upon the "visual relation between a spectator and a spectacle," stating that staring at the disabled body is an act that "registers the perception of difference and gives meaning to impairment by marking it as aberrant" [38] (p. 56). The gaze able-bodied people direct upon the disabled body is usually furtive: we are taught that it is rude to stare so "the disabled body is at once the to-be-looked-at and not-to-be-looked-at, further dramatizing the staring encounter by making viewers furtive and the viewed defensive" [38] (p. 57). The spectator's stare "creates disability as a state of absolute difference rather than simply one more variation in human form," while at the same time "constitutes disability identity by manifesting the power relations between the subject positions of disabled and able-bodied" [38] (p. 57). Media platforms turn this fascination with physical disability into a subversive opportunity to reverse the power structures between the spectacle and the speculator "that elicit responses or persuade viewers to think or act in certain ways" [38] (p. 58). The disabled want to be seen, "inviting the gaze of 
ableist culture" to focus on embodiments of "all that is good with a hyper-ableist philosophy: blurring man-machine, re-enabling disability, blurring the lines between disability and ability" [50] (p. 145). Through the media, disabled people are able to control, construct, and mold social narratives to fit their agendas. The supercrip narrative, once stigmatizing, has become a marketing vehicle of education and product advertising, as well as empowerment for the prosthetically enhanced, with differently constructed bodies striving to break the constraints of a binary dis/ability discourse [33] (p. 80).

Double amputee Hugh Herr is widely known as a staunch advocate of the empowering proprieties of prosthetic technology and a physical representation of the empowered supercrip. Herr regularly appears in YouTube videos, marketing campaigns, or TED Talk presentations to expound upon the possibilities of prosthetic applications, heavily emphasizing a narrative that focuses on the empowering freedom of engineered prosthetics and performing physical feats that are elusive to even "normal" bodies. Herr was severely injured during a mountain climbing incident in his twenties and lost both legs to frostbite. After surveying the "normalizing" prosthetic limbs that were currently available on the market, Herr decided that he was "not handicapped; the technology is" [51]. He began to experiment with unconventional designs that fit a purpose, rather than adhering to normative restrictions. Within weeks of the amputation, Herr resumed climbing and at the same time, he began modifying prosthetics to fit his needs. Working with traditional materials at the time, he cut off a heel to reduce weight, increased his legs' stiffness when it was necessary, added garden rake-like spikes for ice climbing, made feet narrow enough to insert into in small cracks, and even altered his height [52]. Within a year of the amputation, Hugh Herr was able to climb heights beyond the reach of his previously "normal" body.

Herr's progress has been well documented since the time of his accident, transitioning from the glorified supercrip hero of the 1980s into an embodiment of superhuman prowess. In a 2014 TED Talk speech, Herr stated,

A human being can never be 'broken.' Technology is broken. Technology is inadequate. This simple but powerful idea was a call to arms, to advance technology for the elimination of my own disability, and ultimately the disability of others. I began by developing specialized limbs that allowed me to return to the world of rock and ice climbing. I quickly realized that the artificial part of my body is malleable; able to take on any form, any function-a blank slate for which to create, perhaps, structures that could extend beyond biological capability. [53]

In the years that followed, Herr has made continuous breakthroughs, starting with a computer-controlled artificial knee in 2003. In 2004, Herr created the Biomechatronics group at MIT that combines the fields of biology, mechanics, and electronics to restore function to those in need. In 2007, the Biomechatronics team produced a powered ankle-foot prosthesis, which allows an amputee to walk with speed and effort comparable to those with biological legs, called the emPower; a lightweight apparatus that houses 12 sensors, three computers, tensioning springs, and muscle-tendon actuators. The emPower success led Herr's team to further their innovative designs in extreme bionics and build prosthetic legs that not only allow the disabled to walk, but to run, climb, and even dance with ease [53].

The spokesperson for the center of Extreme Bionics as well as product prototype, Herr quips, "I'm kind of what they're selling" [54]. Each presentation Herr gives as a frequent public speaker is a visual display of the agility and capability of his bionic legs. Herr's prosthetics, once makeshift alterations of garden tools he repurposed from his father's garage, are now sleek, balanced, and intuitively responsive. Herr wears pants that are tailored just below his knees, exposing the technology of the bionic legs to the public eye with the company logo proudly displayed on each artificial ankle. With each agile step taken, Hugh Herr embodies the superpowered supercrip narrative as a techno-marvel that attracts the attention of both disabled and normative-bodied consumers. During talks and interviews, Herr constantly directs audience attention to a narrative that emphasizes superhuman capabilities achieved through technology, explaining that with innovative technology his amputation was an advantage, not a disability. Though specialized prosthetics gave him the ability to reach new heights in rock and ice climbing, Herr explained that the double amputation also became a physical advantage, as "his body 
got colder and achier as he climbed but his legs did not. He was able to move faster and higher than before, in part because the amputations had left him 14 pounds lighter" [55]. In an interview, Herr said: "My climbing colleagues first labeled me as 'courageous,' which is always very demeaning... The second I became competitive; I became a threat. I had a few people threaten to amputate their own limbs to achieve the same advantage" [56]. The term "advantage" would continue to appear in conjunction with Herr's prosthetics.

The advantages of prosthetic augmentation as compared to the "natural" body are also frequently debated in sports, with double amputee Oscar Pistorius a prime example. The first amputee to compete in an Olympic track event, Pistorius' qualification to run in the Olympics came into question with the IAAF (International Association of Athletics Federations) in 2008. The IAAF published an amendment of its competition rules in 2007 to enforce a ban on the use of "any technical device that incorporates springs, wheels or any other element that provides a user with an advantage over another athlete not using such a device"; this became a defining moment in prosthetic development [57]. Following the ban, IAAF invited Pistorius to a joint research project that revealed his advantage while running with prosthetics to be overwhelmingly high, leading to the IAAF ruling Pistorius' prostheses ineligible for use in competitions conducted under its rules. Additional studies showed that once a runner on blades accelerates to top speed, one potential advantage lies in the ability to move the prostheses faster and with less effort [58,59]. Similarly, the IAAF barred German Paralympic long jumper Markus Rehm from competing in the 2016 Rio Olympics after Rehm failed to prove his prosthetic leg did not give him "unfair" advantages. Rehm and Pistorius are prominently disabled under the current social definition, yet have been accused of unfair advantages over their peers. This dispute can be understood as a fundamental inquiry into disability and capability. If all sports are meant to be a celebration and display of bodies that transcend physical limitations, why is a celebration of prosthetic athleticism rejected? Traditional sports feature the "human" capacity, with athletes performing "natural" skills; however, with health supplements and analytical training, modern day sports can hardly be seen as exclusive to the boundaries of human physicality [60]. Soon, augmented bodies will offer a performance capacity with which "no 'natural' body could possibly compete"; therefore, the body's boundaries need to expand to include the variations of bodies integrated with technologies we define as posthuman [61].

With articles, interviews, and public speeches meticulously building upon the empowering aspects of technological enhancement; prosthetics, once representing immobility and exclusion, carry infinite possibilities with the application of enhancive technologies. Disability is transformed into capability and disadvantage into advantage [62]. The posthuman body is temporal, malleable, and should be understood in part through advances in technology that "destabilize any 'absolutes' in body construction" [61] (p. 128). The assumptions we rely upon when constructing the rhetoric of ableism rely on a notion of "correct" and "normal" human bodies to which we all must conform in order to be declared fully human [63] (p. 183). In turn, humanity is the end product of a normalizing process in corporeality and embodiment; the body is not simply a natural and enclosed subject but part of a social institution; our understanding of embodiments and corporealities is constantly deconstructed and rebuilt according to social needs, structure, and narrative. Bodies are no longer simply categorized as abled, disabled, or super-abled, but are part of constantly changing sociocultural frames and techno-capacity; what is "natural" is change and adaptation to the alternatives. The posthuman body reveals constant, performative constructions where bodies can be altered and even redesigned. The examples of prosthetic enhancement of real bodies are testimony to the fact that prosthetic technology will continuously push the boundaries of physical limitation, leading to fundamental shifts in normative social paradigms that transform the prosthesis from a symbol of stigma into a highly desirable commodity for generations to come.

\section{Transitioning Boundaries-Building a Posthuman Body of Your own Design}

With this in mind, the body as a social institution is unstable, its boundaries negotiable and in constant transition. The transition from an emphasis on the natural body to the posthuman is, 
as Vaccari stated, an "erosion of the distinction between organism and machine, nature and art, and the biological and engineering sciences" [64] (p. 138). Vaccari's argument focuses on Descartes' philosophical departure from Aristotle's principles of biology. Aristotle's biology principles kept living organisms ontologically bound and whole, differentiating artifacts and organisms through metaphysics that separate the corporeal and material [64-66]. Vaccari cited Descartes' Cartesian mechanism as a rhetoric of posthuman thought, stating that Descartes "blurred the unity and boundaries of living bodies" by uniting bodies and artifacts under the concept of matter [64] (p. 140). He argued that "the only natural norm of the body is the mutual interrelation of the organs; we can easily envision the replacement of certain elements of this arrangement without affecting the 'nature' of the whole" [64] (p. 155). Conventional body boundaries must be replaced by fluidity, in other words, contemporary society is in a position where a hybridity between the body and prostheses is embraced, pursued, and constantly reinvented. Our bodies are posthuman; the cyborg is an evolutionary state as well as the next step of human materiality [67].

In 2011, Herr embellished upon the fluidity of the posthuman body to predict that the prosthesis will become an extension of our physical form:

As we march into this 21 st century, the changes we'll see in prosthetic designs [will be that] the artificial prosthetic will become more intimate with the biological human body. There will be a mergence, if you will. The prosthesis will be attached to the body mechanically by a titanium shaft that goes right into the residual bone, wherein you can't take the artificial limb off. Another intimate connection will be electrical. The nervous system of the human will be able to communicate directly with the synthetic nervous system of the artificial limb. [68]

Neurologically controlled, feeling prosthetics are much more than a supplementary addition to the body; they are evolving into an actual extension of our being. It is prudent to assume that soon our bodies may have little to do with the original state of our birth. Apart from the development in external prosthetics, scientists have also discovered ways to bring the prosthesis into our body by means of transplantation. Organ transplants are an established procedure; however, the need for organ donors far exceeds the supply. An exciting development in the field has been 3D printing technology. Scientists are now able to "print" artificial organs using biomaterials that promise to one day transform the market and become an answer to the donor shortage and organ rejection. Disabled or aging bodies will have the option to "change parts" in order to maintain and even increase physical functionality. As Herr states, "My biological body will degrade in time due to normal, age-related degeneration. But the artificial part of my body improves in time because I can upgrade" [68]. This is no doubt a great step in shaping the human condition at will; we are able to replace our organic bodies with the customizable and upgradable. By means of science and technology we can look forward to a world where physical normalcy and normative boundaries are displaced by a new, creative world of our imaginative design.

In addition to high performance bionic limbs and prosthetic organs, the image of prosthetics is rapidly evolving past the human form to present a variety of designs and functions. Herr is fond of reminding audiences how he "viewed the missing biological part of my body as an opportunity, a blank palette for which to create" [69]. Under the posthuman design, the prosthesis no longer represents a lack in the disabled body, but the freedom and infinite possibilities in altering and transforming the human form $[58,70,71]$. The infinite possibilities of the prosthesis are best embodied by Aimee Mullins, whose public career began as a record-breaking athlete at the Paralympic Games in 1996. Aimee Mullins' legs captured the world's attention not because of their functional innovation, but because of their unconventional design. Mullins opened British fashion designer Alexander McQueen's London show on a pair of hand-carved wooden prosthetic legs made from solid ash. With intricately carved flowers and grape vines, the prosthetics were designed to look like Victorian knee-length boots with a Louis heel, pointed toe, and slim ankle. She wears her "Barbie legs" to formal events and is able to alternate her height between 5 feet, 8 inches to 6 feet, 1 inch. In Matthew Barney's Cremaster 3, Mullins changes between legs shaped like a jellyfish to painted cheetah limbs, legs cast out of dirt, 
and transparent polyethylene legs complete with heels; each change of prosthetics represents a shift in her role and identity in the film. Mullin's legs have come to be associated with discussions about the unstable materiality of human bodies, "her prosthesis ... extends her bodily boundaries and open and problematizes her sense of identity" [71] (p. 33). The fact that the significance of prosthetic devices "has shifted from trying to mimic the human form in order to camouflage, disguise and replace, exhibited symbolic entities which look like machines and evoke a sci-fi futuristic multiplicity of human and post-human bodily imaginaries" ushers in an age of transgressive design and function that reconceptualizes body, material, and embodiment [71] (p. 45).

Mullins believes that the new age of prosthetics "can stand as a symbol that the wearer has the power to create whatever it is that they want to create in that space" [72]. With the infinite possibilities of prosthetic creation, the disabled can become "the architects of their own identities" and the ability to redesign disabled bodies becomes a form of empowerment [72]. The body no longer needs to be accepted in its "as is" condition, but becomes whatever we envision. The possibilities of prosthetic creations reject the conventional definition of less as lack; "the absence of limbs becomes an open-ended possibility to reconfigure the appearance and the functionality of human biology in unprecedented ways" [70] (p. 50). In 2016, San Francisco-based organization KIDmob teamed with 3D-printing and design software company Autodesk to hold a "Superhero Cyborgs" workshop. Superhero Cyborgs encouraged kids—-both with and without disabilities—-to design and build wearable devices that were potential alternatives to traditional upper limb prosthetics. The kids created their own "superpowers" through personalized wearable devices that included a five-nozzle glitter shooter, a prosthetic with a detachable bow and arrow, and an elbow-movement-activated water gun [73]. Prosthetics are undergoing an "incorporation and projecting" of design, "an unstoppable 'difference' that is not about negation but about the alterity of 'becoming' ... [which] challenge simple figuration and fixity" [22] (p. 38). These creative possibilities render the ideal, normalized body obsolete; soon our bodies will either remain in their conventional forms or embrace the conceptual. For future generations, the human form can be whatever we imagine it to be. We will have the power to "customize" the body to adapt to different environments, age, functionality, and individual aesthetics.

The branding of prosthetics with superhero imagery as well as studies in augmented bodies' actual advantages and affirmative power have transformed the disability market. Prosthetics are less representative of stigma and more an invitation to explore the differently abled body's capabilities. In the near future, physical augmentation will no longer be a response to infirmities but a neo-liberalist choice to embrace diverse embodiment. However, as with all neo-liberalist choices, the power to enhance and redesign our bodies comes with social costs and moral responsibilities that must be thoroughly addressed. The questions I propose here are not what we can do with technology, but rather questions of how to reinforce a universal respect for diversity as well as promote equal access to viable resources. The power to genetically alter, bionically substitute, and otherwise hybridize our physical materiality deconstructs past definitions of human corporeality and individual agency. Augmentative technology undoubtedly provides an advantage to enhanced bodies, yet will disability be eliminated in a future where prosthetic enhancement is open to all? Or will biotechnology subject unaltered bodies to an even more severe regime of normalcy so that the "human capital" becomes a new determinant of social caste?

\section{Bioethical Concerns and Uneven Access-Posthuman Disability and Peripheral Bodies}

With the increasingly creative and seamless integration between prostheses and human bodies, "ableism" no longer solely represents physical performances of the body "occurring in natural embodiments and corporealities" [63] (p. 185). The body's boundaries are extended beyond the casing of flesh and bone; the "natural" body becomes the posthuman.

As with all innovative technology, prosthetic extensions come at a cost that raises bioethical concerns. In terms of social costs, critics believe that prosthetic technology will add to the stigmatizing effects of disability simply because these prosthetics will also aid people without disabilities, while the 
disabled remain so. Many believe that prosthetic enhancement will further marginalize disabled people by raising the benchmark for ableism, allowing stigma to continue under a new form and narrative $[50,74,75]$. Susan Wendell posited that advertising the disabled, enhanced hero "may reduce the 'Otherness' of a few people with disabilities, but because it creates an ideal that most people with disabilities cannot meet, it increases the 'Otherness' of the majority of people with disabilities" [76]. Prosthetic enhancement adds to the ableist stigma by asserting that disability is acceptable as long as the disabled are able to receive a prosthetic cure and "pass" as "whole" [34] (p. 24). The supercrip narrative and posthuman biotechnological efforts, while empowering the disabled, are in fact far more concerned with a "transhumanization of ableism" that will "impact what we perceive as healthy bodies leading to the transhumanization of the meaning of health ... the scenario where only certain beyond species-typical body abilities are seen as healthy" [77]. Prosthetically-enhanced physical performance "reifies a particular conception of a normal body, creating an expectation that all disabled bodies should achieve" [61] (p. 56). These expectations include a "new era of disabled athleticism-buffed, muscular, yet technologically supplemented bodies-promising all of the transcendent capacity a hyper-medicalized culture could offer" while demonstrating a seamless connectivity between the corporeal body and the prosthesis [18] (p. 117). Cynthia Bruce worried that an insatiable pursuit of physical enhancement will further the benchmark of ableist marginalization for disabled people [75]. The biggest question is if the disabled will be further excluded from society "for not having hyper or super abilities, which may be the primary feature for defining a 'normal' person in the coming age" [34] (p. 29). Certainly, an amputee with a bionic leg would enjoy more physical mobility than an amputee with a traditional prosthesis and be seen as able in comparison; ableism is therefore determined by prosthetic performance $[74,78,79]$.

In terms of monetary cost, scholars and activists such as Goggin and Newell questioned the "'commonsense' notion of people with disabilities inherently benefiting from new technologies" [80]. In 2013, ballroom dancer Adrienne Haslet-Davis' leg was amputated after being hit by shrapnel in the Boston marathon bombing. Haslet-Davis later became part of Hugh Herr's "New Bionics Let Us Run, Climb and Dance" TED Talk presentation, where she spun and floated across the floor with the latest bionic limb, to a standing ovation. As incredible as the moment seemed, Haslet-Davis was only a test participant; she was not able to keep the prototype that cost millions to reproduce. Herr's facility fit rock climber Jim Ewing in 2018 with a newly designed ankle-foot prosthetic that is thought to be responsive and allows him to feel the appendage through neuro-stimulation, yet the prosthetic is also a prototype that Ewing will eventually have to return. Haslet-Davis and Ewing were both part of a research project and would not be able to keep the advanced prosthetics. However, the exorbitant cost of high-functioning bionic limbs begs the question of who will be able to afford these prostheses once they are available on the market. In "A Leg to Stand on," Vivian Sobchack noted that her own "rather ordinary" AK leg cost $\$ 10,000$ to $\$ 15,000$. The well-known sprinting "cheetah leg" is at least $\$ 20,000$ per leg, whereas stair-climbing bionic legs range from $\$ 40,000$ to $\$ 50,000$, a price range that is hardly affordable for the average person [81] (p. 31). Advanced prosthetics are not covered by health insurance policies, therefore the access to such technology is rapidly becoming a reflection of financial power and serves as a watershed between the advantaged and disadvantaged [34] (p. 33).

In the glamorous façade of twenty-first century biotechnological progress, prominent rifts have begun to surface. Disabled people using the latest assistive technologies are a natural constituency for prosthetic enhancement, yet disability remains rooted in "the political economic realities of capitalism" [82] (p. 199). The paradox between the commodification of assistive technology and the social reality of disability is a prominent issue, with Snyder and Mitchell arguing that

the particularities of bodily accommodations necessarily send people with disabilities into circulation as consumers of medical and social services assistance. This entry of disabled "consumers" into market systems becomes an odd and nuanced affair in that the basis of those classified as consumers usually require "purchasing power," the one thing that the majority of disabled people do not possess. [18] (pp. 114-115) 
At present, biotechnological marvels remain a form of class consumption. Advanced technology is only open to those who can afford the purchase, causing people in one country to experience the same impairment differently, based on their socioeconomic status. The "have nots" and the "haves" will lead directly to an "ability divide" that is not only reflected by individuals, but sets a division on a global scale [83]. Since "all subjects in modern, liberal, technologized, and consumerist social orders are medical subjects—or perhaps more precisely medical consumers," the main disabling factor is no longer impairment but access to technology [84]. In other words, this new model of disability is very likely to "generate new ability divides as well as gradations of wealth from techno-poor to techno-rich" [50] (p. 161).

James I. Charlton examined the relationship between the current socioeconomic system and the disabled experience to reveal a commonality between disabled persons and the "world's poor" in impoverished areas all over the globe [82] (p. 195). Technological advancement "does not occur as something separate from ideology and stigma" but rather reinforces stigma under a different structure of disabling due to disabled and disadvantaged persons' peripheral alienation [82]. Charlton believed this structuring force to be "the commodity form" that is "control (rooted in unequal relationships), hierarchy, commodification, and mystification" [82] (p. 196). Disabled persons are often situated in the poorest and most marginalized communities, resulting in a "double outcast" phenomenon that Charlton sees as a "pattern of periphery, even in the most varied places, that reveals a deep force immanent throughout the world system that is both hidden and hides many reasons for the disability condition" [82] (p. 196). An example of this pattern is seen in Laos, where many victims of war remain in handmade stumps and pegs, whereas prosthetics provided by rehabilitation centers are plastic, mannequin-like affairs operated by pulling a belt [84]. Regardless of where they are, the majority of people with disabilities remain on the periphery and are excluded from positions of capitalist gain.

Disabled persons are "locked into subalternity, the underclass, institutionalized dependencies, the peripheral everywhere" [82] (p. 198). Without access to technology, disabled bodies remain peripheral bodies; disabled people are "outsiders in core capitalist countries" [82] (p. 195). In short, stigmatizing social structures have not changed, the "conceptual schemas and mind maps of ableism" remain intact, while the "pool of the remnant, the 'have nots' and 'not quites,' grows larger and more diverse" [74] (p. 63). Access to technology is determined by an economic difference that is reflected in social differences; in this day and age, restricted access to technological devices and knowledge is arguably more disabling than limited mobility and is a criterion that applies to all of us. Access to technology determines the opportunities of an individual and is rapidly overtaking physical ability as a main disabling factor. Apart from relying on close supervision to construct an equal access to technology and information, how are we to bridge the gap between the haves and have-nots?

\section{Concluding Thoughts-Bridging the Gap through Interdisciplinary Education}

Disability scholarship and posthuman discourse are tasked with ethical debates that go above and beyond merely extending the boundaries of what we perceive as human. A disability-conscious bioethical viewpoint provides focus for social justice and equality; in addition to emphasizing an inclusive participation of people with disabilities in society, a respect for difference and accessibility are needed to prepare humanity for the changes ahead. Finding new and alternative modes of political and ethical agency for our technologically-mediated world is imperative to closing the differences between techno-capitalist gain and bioethical concerns. One solution to this challenge is to provide an interdisciplinary approach that balances the debate between scientific advance, capital gain, and social equality. In order to embrace "the liberatory and even transgressive potential of these technologies," we must also take precautions against "those who attempt to index them to either a predictable conservative profile, or to a profit-oriented system" [10] (p. 58). Braidotti urged us to focus on a "technological mediation" that is central to "a new vision of posthuman subjectivity and ... provides the grounding for new ethical claims" [10] (p. 90). An interdisciplinary, bioethical vision exhorts us to "move forward into multiple posthuman futures ... in a new global context and to develop an ethical 
framework worthy of our posthuman times" [10] (p. 150). Creative, intersecting thought provides a way for new alliances between the humanities and the sciences, resulting in emerging fields such as the medical humanities and interdisciplinary education [10] (p. 145). Garland-Thomson, in particular, advocated for a "disability cultural competence" that enforces the knowledge of interdisciplinary studies in both practice and policy [85] (p. 328). Converting disability theory into usable disability bioethics, she argued, will "strengthen the cultural, political, institutional, and material environment in which people with disabilities can most effectively flourish" [85] (p. 331). Certainly, an interdisciplinary, bioethical vision invites more thought about creating fair opportunities for the disabled, as well as builds a sustainable infrastructure that embraces diversity and allows for equal access.

The future of the posthuman lies not in the unbound efforts of technological growth, but in an interdisciplinary education that combines the humanities with scientific knowledge to teach a new and alternative mode of agency. Part of building a sustainable, equal future is creating equal opportunities through education. An interdisciplinary education that publicizes scientific knowledge, ethical guidelines, and open access should be as important as the technology that drives our progress. The focus of interdisciplinary education is not a "tur[n] backwards to a nostalgic vision of the Humanities as the repository and the executors of universal transcendental reason and inherent moral goodness," but should emphasize a move forward into multiple posthuman futures that provide equal opportunities in its stead [10] (p. 150). Similarly, Aoun appealed for a reformation in different approaches toward teaching the humanities and expounded upon the significance of human agency and creativity in influencing the impact of technology to propose a learning model of "humanics" [86]. This integrative alliance between the sciences and the humanities has become highly important, not only to address the new ecologies of becoming and belonging, but as a necessary response to the subsequent ecopolitical impact. Interdisciplinary education is crucial to promoting technological literacy, as well as to increasing equal access and sustainable development.

Interdisciplinary education paves the way for an equal future, taking into account the elements of creativity and imagination that allow us to embrace diversity and pursue alternative forms of the posthuman. The human race should be able to improve upon our physical conditions, with the acknowledgement that all forms of enhancement and prosthetic extensions are just as much part of our embodied experience as flesh and bone. However, this turn to posthuman embodiment should not be restricted to merely applauding the marvels of biotechnology and commodifying futuristic design, but should also include diverse forms of the differently abled, whether the body is enhanced or not. In other words, we can embrace biotechnology as a welcome form of choice that should not be considered mandatory, nor should it be a consumerist luxury only made available to the financially able. Above all, interdisciplinary humanities must include discussions about providing equal opportunities to all its adherents. This innovative agenda will continue to inspire affirmative alternatives in new forms of subjectivity, as well as urge us to rethink embodiment in a sustainable future.

Funding: This research received no external funding.

Conflicts of Interest: The author declares no conflict of interest.

\section{References}

1. Seaman, M.J. Becoming More (Than) Human: Affective Posthumanisms, Past and Future. J. Narrat. Theory 2007, 37, 246-275. [CrossRef]

2. Smith, M.; Morra, J. (Eds.) The Prosthetic Impulse: From a Posthuman Present to a Biocultural Future; MIT Press: Cambridge, MA, USA, 2007.

3. Kline, R. Where are the Cyborgs in Cybernetics? Soc. Stud. Sci. 2009, 39, 331-362. [CrossRef]

4. Mitchell, D.T.; Snyder, S.L. Narrative Prosthesis: Disability and the Dependencies of Discourse; University of Michigan Press: Ann Arbor, MI, USA, 2014.

5. Hayles, N.K. How We Became Posthuman: Virtual Bodies in Cybernetics, Literature, and Informatics; University of Chicago Press: Chicago, IL, USA, 1999. 
6. Haraway, D. A Cyborg Manifesto: Science, Technology, and Socialist-Feminism in the Late 20th Century. In The International Handbook of Virtual Learning Environments; Weiss, J., Nolan, J., Hunsinger, J., Trifonas, P., Eds.; Springer: Dordrecht, The Netherlands, 2006.

7. Rifkin, J. The Biotech Century; Penguin: New York, NY, USA, 1998.

8. Blackmann, L. The Body: Key Concepts; Berg: Oxford, UK, 2008.

9. Siebers, T. Disability Theory; University of Michigan Press: Ann Arbor, MI, USA, 2008.

10. Braidotti, R. The Posthuman; Polity: Oxford, UK, 2013.

11. Crilley, M. Material Disability: Creating New Paths for Disability Studies. CEA Crit. 2016, 78, 306-311. [CrossRef]

12. Nayar, P.K. Posthumanism; Polity: Oxford, UK, 2014.

13. Goodley, D.; Runswick-Cole, K.; Lawthom, R. Posthuman Disability Studies. Subjectivity 2014, 7, 342-361. [CrossRef]

14. Davis, L. The End of Identity Politics and the Beginning of Dismodernism: On Disability as an Unstable Category. In The Disability Studies Reader, 2nd ed.; Davis, L.J., Ed.; Routledge: London, UK, 2006; pp. 231-242.

15. Shildrick, M. Leaky Bodies and Boundaries: Feminism, Postmodernism and (Bio)ethics; Routledge: London, UK, 1997.

16. Murry, S.F. Disability and the Posthuman: Bodies, Technology and Cultural Futures; Liverpool UP: Liverpool, UK, 2020.

17. Wolfe, C. What is Posthumanism? University of Minnesota Press: Minneapolis, MN, USA, 2010.

18. Mitchell, D.T.; Snyder, S.L. The Biopolitics of Disability: Neoliberalism, Ablenationalism, and Peripheral Embodiment; University of Michigan Press: Ann Arbor, MI, USA, 2015.

19. Lee, B.Y. An Overlooked and Growing Market: People with Disabilities; Forbes: Jersey City, NY, USA, 2016.

20. Garland-Thomson, R. Integrating Disability, Transforming Feminist Theory. NWSA J. 2002, 14, 1-32. [CrossRef]

21. McRuer, R. Cripping Queer Politics, or the Dangers of Neoliberalism. Sch. Fem. Online 2012, 10, 1-2.

22. Davis, L.J. Bending Over Backwards: Disability, Dismodernism, and Other Difficult Positions; New York University Press: New York, NY, USA, 2002.

23. Pullin, G. Design Meets Disability; MIT Press: Cambridge, MA, USA, 2009.

24. Tusler, A. How to Create Disability Access to Technology: Best Practices in Electronic and Information Technology Companies; World Institute on Disability: Berkley, CA, USA, 2005.

25. Bates, D. 10 Ways to Target the Disability Market \& Keep a Competitive Edge. Available online: https://www.linkedin.com/pulse/20140703000007-11466134-top-10-ways-to-market-to-people-withdisabilities-and-boost-your-roi (accessed on 9 June 2020).

26. Trevisan, F. Disability Rights Advocacy Online: Voice, Empowerment and Global Connectivity; Routledge: New York, NY, USA, 2017.

27. Haller, B.A.; Ralph, S. Are Disability Images in Advertising Becoming Bold and Daring? An Analysis of Prominent Themes in US and UK Campaigns. Disabil. Stud. Q. 2006, 26. [CrossRef]

28. Davis, L. The End of Normal: Identity in a Biocultural Era; University of Michigan Press: Ann Arbor, MI, USA, 2014.

29. Schalk, S. Reevaluating the Supercrip. J. Lit. Cult. Disabil. Stud. 2016, 10, 71-86. [CrossRef]

30. Alaniz, J. Supercrip: Disability and the Silver Age Superhero. Int. J. Comic Art 2004, 6, 304-324.

31. Howe, P.D. Cyborg and Supercrip: The Paralympics Technology and the (Dis)Empowerment of Disabled Athletes. Sociology 2011, 45, 868-882. [CrossRef]

32. Silva, C.F.; Howe, P.D. The (In)Validity of Supercrip Representation of Paralympian Athletes. J. Sport Soc. Issues 2012, 36, 174-194. [CrossRef]

33. Clare, E. Exile and Pride: Disability, Queerness, and Liberation, 1st ed.; South End Press: Cambridge, MA, USA, 1999.

34. Sun, H.-Y. Prosthetic Configurations and Imagination: Dis/ability, Body, and Technology. Concentric Lit. Cult. Stud. 2018, 44, 13-39.

35. Linton, S. My Body Politic: A Memoir; University of Michigan Press: Ann Arbor, MI, USA, 2006.

36. Stobbart, D. Mad Max and Disability: Australian Gothic, Colonial, and Corporeal (Dis)possession. Stud. Gothic Fict. 2018, 6, 65-72. [CrossRef]

37. Grue, J. The Problem of the Supercrip: Representation and Misrepresentation of Disability. In Disability Research Today: International Perspectives; Routledge: London, UK, 2015; pp. 204-218. 
38. Garland-Thomson, R. The Politics of Staring: Visual Rhetorics of Disability in Popular Photography. In Disability Studies: Enabling the Humanities; Snyder, S.L., Brueggemann, B.J., Garland-Thomson, R., Eds.; Modern Language Association of America: New York, NY, USA, 2002; pp. 56-75.

39. Berger, R.J. Disability and the Dedicated Wheelchair Athlete: Beyond the Supercrip Critique. J. Contemp. Ethnogr. 2008, 37, 647-678. [CrossRef]

40. Ripat, J.; Woodgate, R. The Intersection of Culture, Disability and Assistive Technology. Disabil. Rehabil. Assist. Technol. 2011, 6, 87-96. [CrossRef]

41. Wise, P.H. Emerging Technologies and Their Impact on Disability. Future Child. 2012, 22, 169-191. [CrossRef]

42. Allan, K. Disability in Science Fiction: Representations of Technology as Cure; Macmillan: New York, NY, USA, 2013.

43. Wälivaara, J. Blind Warriors, Supercrips, and Techno-Marvels: Challenging Depictions of Disability in Star Wars. Pop. Cult. 2018, 51, 1036-1056. [CrossRef]

44. Chemers, M.M. Mutatis Mutandis: An Emergent Disability Aesthetic in 'X-2: X-Men United'. Disabil. Stud. Q. 2004, 24, 1.

45. Talaty, M.; Esquenazi, A.; Briceño, J. Differentiating ability in users of the ReWalkTM powered exoskeleton: An analysis of walking kinematics. In Proceedings of the 13th International Conference on Rehabilitation Robotics, Seattle, WA, USA, 24-26 June 2013; pp. 1-5.

46. Song, Z.; Tian, C.; Dai, J.S. Mechanism Design and Analysis of a Proposed Wheelchair-exoskeleton Hybrid Robot for Assisting Human Movement. Mech. Sci. 2019, 10, 11-24. [CrossRef]

47. Shamo, L. These Bionic Arms Make Kids Feel Like Superheroes. Available online: https://www. businessinsider.com.au/open-bionics-prosthetic-arms-2018-2 (accessed on 9 June 2020).

48. Smith, S. Limbitless Solutions': The Prosthetic Arm, Iron Man and the Science Fiction of Technoscience. Med. Hum. 2016, 42, 259-264. [CrossRef]

49. Mitchell, D.T.; Snyder, S.L. Cultural Locations of Disability; University of Chicago Press: Chicago, IL, USA, 2006.

50. Goodley, D. Dis/ability Studies: Theorising Disablism and Ableism; Routledge: London, UK, 2014.

51. Helgensen, S. Hugh Herr Wants to Build a More Perfect Human. Strateg. Bus. 2016, 85, 1-12.

52. Kiss, J. What If A Bionic Leg Is So Good that Someone Chooses to Amputate? Available online: https: //www.theguardian.com/technology/2015/apr/09/disability-amputees-bionics-hugh-herr-super-prostheses (accessed on 9 June 2020).

53. Herr, H. The New Bionics that Let Us Run, Climb and Dance. Available online: https://www.youtube.com/ watch?app=desktop\&persist_app $=1 \& v=C D s N Z J T W w 0 w$ (accessed on 9 June 2020).

54. Balf, T. The Biomechatronic Man. Available online: https://www.outsideonline.com/2238401/biomechatronicman (accessed on 9 June 2020).

55. Adelson, E. Best Foot Forward. Available online: https://www.bostonmagazine.com/2009/02/18/best-footforward-february/ (accessed on 15 June 2020).

56. Rosenberg, J. Who Says Hugh Herr Can't Climb (Part I). Available online: https://www.youtube.com/watch? v=z6_0nI5U-Qg (accessed on 12 February 2020).

57. Brueggemann, G.P.; Arampatzis, A.; Emrich, F.; Potthast, W. Biomechanics of double transtibial amputee sprinting using dedicated sprinting prostheses. Sports Technol. 2008, 1, 220-227. [CrossRef]

58. Karpin, I.; Mykitiuk, R. Going out on a Limb: Prosthetics, Normalcy and Disputing the Therapy/Enhancement Distinction. Med. Law Rev. 2008, 16, 413-436. [CrossRef] [PubMed]

59. Burkett, B.; McNamee, M.; Potthast, W. Shifting boundaries in sports technology and disability: Equal rights or unfair advantage in the case of Oscar Pistorius? Disabil. Soc. 2011, 26, 643-654. [CrossRef]

60. Miah, A. Genetically Modified Athletes: Biomedical Ethics, Gene Doping and Sport; Routledge: London, UK, 2004.

61. Booher, A.K. Prosthetic Configurations: Rethinking Relationships of Bodies, Technologies, and (Dis)Abilities. Ph.D. Thesis, The Graduate School of Clemson University, Clemson, SC, USA, December 2009.

62. Brey, P.A.E. Human Enhancement and Personal Identity. In New Waves in Philosophy of Technology; Berg Olsen, J.K., Selinger, E., Riis, S., Eds.; Palgrave: New York, NY, USA, 2008; pp. 169-185.

63. Monceri, F. The Nature of the 'Ruling Body': Embodiment, Ableism and Normalcy. Teoria 2014, 34, $183-200$.

64. Vaccari, A. Dissolving Nature: How Descartes Made Us Posthuman. Techné Res. Phil. Technol. 2012, 16, 138-186. [CrossRef]

65. Symons, J. The Individuality of Artifacts and Organisms. Hist. Phil. Life Sci. 2010, 32, 233-246.

66. Bianchi, E. Aristotle's Organism, and Ours. In Contemporary Encounters with Ancient Metaphysics; Greenstine, A.J., Johnson, R.J., Eds.; Edinburgh University Press: Edinburgh, UK, 2017; pp. 138-157. 
67. Barfield, W. The Process of Evolution, Human Enhancement Technology, and Cyborgs. Philosophies 2019. [CrossRef]

68. The Double Amputee Who Designs Better Limbs. Available online: https://www.npr.org/2011/08/10/ 137552538/the-double-amputee-who-designs-better-limbs (accessed on 10 May 2020).

69. A Bionic Man: Hugh Herr Strides Forward on Next-Generation Robotic Legs. Available online: https: //www.autodesk.com/redshift/hugh-herr-robotic-legs/ (accessed on 23 April 2020).

70. Neicu, M. Prosthetics Imagery: Negotiating the Identity of Enhanced Bodies. Platform 2012, 6, 42-60.

71. Tamari, T. Body Image and Prosthetic Aesthetics: Disability, Technology and Paralympic Culture. Body Soc. 2017, 23, 25-56. [CrossRef]

72. My 12 Pairs of Legs. TEDTalk. Available online: https://www.ted.com/talks/aimee_mullins_my_12_pairs_ of_legs?language $=\mathrm{mg}$ (accessed on 23 April 2020).

73. Hullinger, J. This Girl Designed Her Own Superhero Prosthetic Arm, And It Shoots Sparkles. Fast Company. Available online: https://www.fastcompany.com/3058221/this-girl-designed-her-own-superheroprosthetic-arm-and-it-shoots-sparkles?utm_source=mailchimp\&utm_medium=email\&utm_campaign= fast-company-daily-newsletter\&position=3\&partner=newsletter\&campaign_date=03282016 (accessed on 23 April 2020).

74. Kumari Campbell, F. Contours of Ableism: The Production of Disability and Abledness; Palgarave: New York, NY, USA, 2009.

75. Bruce, C. Rev. of Dis/Ability Studies: Theorizing Disableism and Ableism, by Dan Goodley. Can. J. Disabil. Stud. 2016, 5, 178-183. [CrossRef]

76. Wendell, S. The Rejected Body: Feminist Philosophical Reflections on Disability; Routledge: New York, NY, USA, 1996.

77. Wolbring, G. Expanding Ableism: Taking down the Ghettoization of Impact of Disability Studies Scholars. Societies 2012, 2, 75-83. [CrossRef]

78. Suarez-Villa, L. Globalization and Technocapitalism: The Political Economy of Corporate Power; Routledge: New York, NY, USA, 2016.

79. Wälivaara, J. Marginalized Bodies of Imagined Futurescapes: Ableism and Heteronormativity in Science Fiction Munch's Painting? Painting Reproductions on Display. Cult. Unbound J. Curr. Cult. Res. 2018, 10, 226-245. [CrossRef]

80. Goggin, G.; Newell, C. Digital Disability: The Social Construction of Disability in New Media; Rowman \& Littlefield: London, UK, 2003.

81. Sobchack, V. A Leg to Stand on: Prosthetics, Metaphor, and Materiality. In The Prosthetic Impulse: From a Posthuman Present to a Biocultural Future; Smith, M., Morra, J., Eds.; MIT Press: Cambridge, MA, USA, 2006; pp. $2-41$.

82. Charlton, J.I. Peripheral Everywhere. J. Lit. Cult. Disabil. Stud. 2010, 4, 195-200. [CrossRef]

83. Wolbring, G. The Politics of Ableism. Development 2018, 51, 252-258. [CrossRef]

84. Bulky, Medieval-Looking Stumps: Laos Amputees Make Their Own Prosthetics. The Irish Times. Available online: https://www.irishtimes.com/news/world/asia-pacific/bulky-medieval-looking-stumpslaos-amputees-make-their-own-prosthetics-1.3082794 (accessed on 7 May 2020).

85. Garland-Thomson, R. Disability Bioethics: From Theory to Practice. Kennedy Inst. Ethics J. 2017, $27,323-339$. [CrossRef]

86. Aoun, J.E. Robot-Proof: Higher Education in the Age of Artificial Intelligence; MIT Press: Cambridge, MA, USA, 2018.

(C) 2020 by the author. Licensee MDPI, Basel, Switzerland. This article is an open access article distributed under the terms and conditions of the Creative Commons Attribution (CC BY) license (http://creativecommons.org/licenses/by/4.0/). 